study in which indicators of insulin sensitivity were associated with suicide risk. ${ }^{1}$ The explanation for the reverse $\mathrm{J}$ shaped association seen when diabetes was included as a fifth category alongside insulin resistance may be due to patients with a clinical diagnosis of diabetes developing depression as a result of this diagnosis.

We based our assessment of depression on current use of medication and self reports of past diagnoses and current mood rather than clinical assessment with international diagnostic criteria. However, the consistency of our findings across the three different assessments supports a causal association, and any measurement error in our assessment of depression would tend to dilute the results. Insulin resistance is positively associated with diabetes and cardiovascular disease, and we do not believe that our results should be used to discourage appropriate interventions to prevent and treat insulin resistance. Further, these are novel findings and need to be replicated in other studies. However, if our findings are confirmed there may be an indication for assessing depressive symptoms among individuals receiving treatments that affect insulin resistance, since depressive symptoms are often disabling and could affect compliance with treatment and quality of life.

The British Women's Heart and Health Study is codirected by SA, Peter Whincup, Goya Wannamethee, and DAL. We thank Carol Bedford, Alison Emerton, Nicola Frecknall, Karen Jones,
Rita Patel, Mark Taylor, and Katherine Wornell for collecting and entering data, all of the general practitioners and their staff who have supported data collection, and the women who have participated in the study.

Contributors: All authors developed the study aim and design. DAL undertook the initial analysis and coordinated writing of the paper. All authors contributed to the final version. DAL acts as guarantor.

Funding: The British Women's Heart and Health Study is funded by the Department of Health. DAL was funded by a Medical Research Council/Department of Health training fellowship when this work was undertaken and is now funded by a Department of Health career scientist award. The views expressed in this publication are those of the authors and not necessarily those of any of the funding bodies.

Competing interests: None declared.

Ethical approval: Ethics committee approvals were obtained for the British Women's Heart and Health Study.

(Accepted 30 September 2003)

Golomb BA, Tenkanen L, Alikoski T, Niskanen T, Manninen V, Huttunen $\mathrm{M}$, et al. Insulin sensitivity markers: predictors of accidents and suicides in Helsinki Heart Study screenees. J Clin Epidemiol 2002;55:767-773.

2 Frayn K, Kingman S. Dietary sugars and lipid metabolism in humans. Am J Clin Nutr 1995;62(suppl):S250-263.

3 Lipsett D, Mandras B, Wurtman R, Munro H. Serum tryptophan level after carbohydrate ingestion. Selective decline in non-albumin-bound tryptophan coincident with reduction in serum free fatty acids. Life Sci 1973;9:215-19.

4 Lawlor DA, Ebrahim S, Davey Smith G. Socioeconomic position in childhood and adulthood and insulin resistance syndrome: cross-sectional curvey using data fom the British women's heart and heath study. BMJ 2002:325:805-07.

5 Erasmus Universiteit Rotterdam. EuroQOL. An instrument to value health www.eur.nl/bmg/imta/eq-net/EQ5d.htm (accessed 29 Oct 2003). (Accepted 30 September 2003)

\title{
Drug points
}

Department of Psychiatry,

Haukeland

University Hospital

N-5021 Bergen,

Norway

Inger Marie Waage medical consultant

Regional Drug

Information Centre

(RELIS Vest),

Haukeland

University Hospital

Ane Gedde-Dahl

pharmacist

Correspondence to:

I M Waage, Solli

Nervesanatorium,

Osveien 15, N-5227

Nesttun, Norway

inger.waage@

helse-bergen.no

BMJ 2003;327:138
Pulmonary embolism possibly associated with olanzapine treatment

Inger Marie Waage, Ane Gedde-Dahl

Antipsychotic drugs have been associated with an increased risk of venous thromboembolism. ${ }^{1}$ We report for the first time the case of a patient who developed a pulmonary embolism after starting treatment with olanzapine.

A 28 year old man was admitted to hospital due to a psychotic disorder. Treatment with olanzapine $(10 \mathrm{mg} /$ day) was started, and the dose was gradually increased to $30 \mathrm{mg}$ /day. He also received levomepromazine $(50 \mathrm{mg}$ / day), oxazepam (10 mg/day), and flunitrazepam (1 mg/ day). After 10 weeks, the patient complained of respiratory pain and he had two episodes of haemoptysis. Clinical examination showed no auscultatory findings, no dyspnoea, no tachypnoea, no fever, and normal blood pressure and heart rate. Blood analysis showed raised concentrations of $\mathrm{C}$ reactive protein $(113 \mathrm{mg} / \mathrm{l}$ (normal range $<10 \mathrm{mg} / \mathrm{l})$ ), fibrinogen (6 $\mathrm{g} / \mathrm{l}(2-4 \mathrm{~g} / \mathrm{l}))$, and D-dimer $(0.89 \mathrm{mg} / \mathrm{l}(<0.50 \mathrm{mg} / \mathrm{l}))$. Spiral computed tomography showed a pulmonary embolism in the left lower lobe. Standard anticoagulant treatment was started, and the patient recovered. Olanzapine was discontinued, and his medication changed to quetiapine.

Recent reports suggest an association between clozapine and venous thromboembolic events. ${ }^{2-5}$ However, thromboembolic complications have not previously been described in patients taking olanzapine. The sedating effects as well as the weight gain associated with this antipsychotic treatment can lead to a more sedentary lifestyle, thus creating predisposing conditions for venous thrombosis. In this case, the patient was overweight (body mass index 28.5), but his weight had not substantially changed since starting to take olanzapine. He was otherwise healthy, and his level of physical activity was normal. Tests for possible coagulation disorders-including tests for antiphospholipid antibodies (immunoglobulin lupus anticoagulants and anticardiolipin antibodies), mutation of the methylenetetrahydrofolate reductase C677T thermolabile variant, prothrombin G20210A mutation, activated protein $\mathrm{C}$ resistance, protein $\mathrm{C}$, protein $\mathrm{S}$, antithrombin III, and homocysteine-did not show any underlying risk factors. This leaves the question of the medication's possible direct causal effect.

Contribution: The report was drafted and edited by both authors. IMW was responsible for the clinical care of the patient and is the guarantor.

Funding: None

Competing interests: IMW has received reimbursement for attending conferences from Lundbeck, Pfizer, and AstraZeneca and has been paid consultant fees by AstraZeneca.

1 Hägg S, Spigset O. Antipsychotic-induced venous thromboembolism. A review of the evidence. CNS Drugs 2002;16:765-76.

Walker AM, Lanza LL, Arellano F, Rothman KJ. Mortality in current and former users of clozapine. Epidemiology 1997;8:671-7.

Hägg S, Spigset O, Söderström TG. Association of venous thromboembolism and clozapine. Lancet 2000:355:1155-6.

Knudson JF Kortepeter C, Dubitsky GM, Ahmad SR, Chen M. Antipsychotic drugs and venous thromboembolism. Lancet Anto0.356.250-3.

5 Selten JP, Büller H. Clozapine and venous thromboembolism: further evidence.J Clin Psychiatry 2003;64:609. 